\title{
Call for tighter controls on transgenic foods
}

\section{David Spurgeon, Montreal}

A senior panel of scientific experts has surprised Canadian regulators - and many Canadians - by calling for far tighter regulation of genetically modified (GM) foods.

The recommendations made by the panel from the Royal Society of Canada (RSC) netpens. Most importantly, the panel rejects the doctrine of 'substantial equivalence', by which regulators treat the approval of GM crops as though they were much the same as conventionally grown crops.

The panel says that approval of new environment or as food should be based on "rigorous scientific assessment of their potential for causing harm”. Such tests "should replace the current regulatory reliance on 'substantial equivalence' as a decision threshold", it declares.

The RSC panel, which prepared its report for the Canadian government's scientific and include a ban on growing GM fish in coastal transgenic organisms for release into the

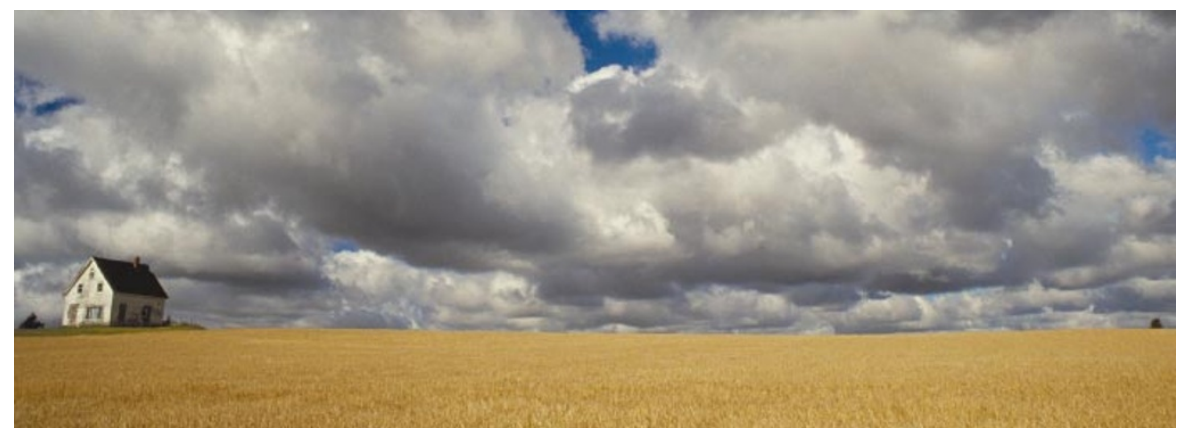

Equal rights? GM crops should not be treated as 'substantially equivalent' to other plants, says panel. regulatory agencies, says that the testing should be done in "open consultation" with the scientific community and that the results should be monitored, in public, by a panel of "experts from all sectors".

New technologies should not be presumed safe unless there is a reliable scientific basis for considering them to be so, the report adds. And "the primary burden of

\section{Physicists worried by grant reforms}

\section{David Adam, London}

Britain's Particle Physics and Astronomy

Research Council (PPARC) is to require

high-energy physicists and astronomers to compete head-to-head for project funding for the first time.

The PPARC was formed in 1994 as the main UK research agency for two disciplines which each rely heavily on the long-term planning of expensive facilities. But until now, its advisory and peer-review structure has been firmly divided between separate arms for astronomy and high-energy physics.

Some high-energy physicists have

expressed concerns about the new structure, which is expected to be approved by the PPARC's governing council this week. The physicists fear that their projects, which often involve years of experiment design and construction, may lose out in direct competition with equally expensive but more rapidly productive astronomy projects.

Under the new structure, a single panel will review and approve small project grants in both astronomy and high-energy physics, helped by appropriate specialists. Funds for larger projects, costing up to $\mathfrak{E 3}$ million (US $\$ 4.4$ million), will be controlled by the council's main scientific committee.

John Garvey, a high-energy physicist at the University of Birmingham and a member of the PPARC panel convened to review its structure, says that his peers' earlier concerns have been addressed by the latest plan. "We now have something on the table

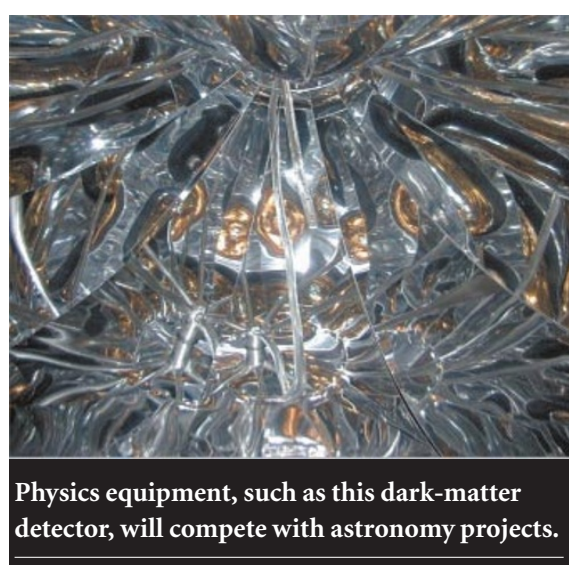

that everyone broadly agrees to," he says. "But at the beginning I do think there was a lack of understanding that particle physicists are experimentalists and astronomers are observers, and that the problems we face pursuing our science are different," he adds. The high-energy physicists advising the panel will now serve for three years, bringing more continuity, Garvey says.

"This is a change, and change gets people worried," admits PPARC chief executive Ian Halliday. "But I think the fears of some in the particle-physics community are unjustified. We don't have any hidden agendas." He acknowledges that the current system is effective, but says that the new structure will "bring greater focus,

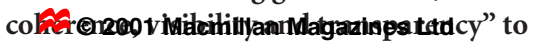
decision-making. proof [should] be upon those who would deploy food biotechnology products to carry out the full range of tests necessary to demonstrate reliably that they do not pose unacceptable risks".

The best scientific methods should be used to reduce uncertainties about risks to human health, the ecosystem and biodiversity, and "approval of products with these potentially serious risks should await the reduction of scientific uncertainty to minimum levels", the report adds.

The panel also says that potential environmental risks posed by GM fish should be assessed on a population-by-population basis. It adds that comprehensive research on the interactions between wild and farmed fish is needed before the risks posed by GM fish can be assessed.

The report contends that regulatory agencies should be more transparent about the science on which their decisions are based, and should take care to maintain a neutral stance in their public statements about the risks and benefits of biotechnology.

It also calls on the Canadian Biotechnology Advisory Commission to "review problems related to the increasing domination of the public research agenda by private, commercial interests".

The recommendations have been widely interpreted in Canada as a reprimand for the GM crops. But Conrad Brunk, academic dean at Conrad Grebel College at the University of Waterloo, Ontario, and a co-chair of the panel, claims that they are not very different from recent statements made in the United States and the European Union on the safety of GM foods.

"We were asked to forecast the directions of the technologies as they become more sophisticated and complex, and to make recommendations about the scientific capacity that would be needed to regulate them," he says. "Unfortunately, our recommendations are being interpreted by some people in the Canadian regulatory agencies as severe criticism of what they're doing now."

http://www.rsc.ca/foodbiotechnology/indexEN.html government's previous readiness to approve 